\title{
The implementation of a probabilistic learner model in LMS-LD course creation application COPROLINE
}

\author{
Mouenis Anouar Tadlaoui ${ }^{1 *}$, Fauzi El Moudden ${ }^{1}$ and Mohamed Khaldi ${ }^{2}$ \\ Research Scholar, Abdelmalek Essaâdi University, Faculty of Sciences, Lirosa, Tétouan, Morocco ${ }^{1}$ \\ Professor, Abdelmalek Essaâdi University, Faculty of Sciences, Lirosa, Tétouan, Morocco ${ }^{2}$
}

Received: 28-February-2019; Revised: 11-June-2019; Accepted: 17-June-2019

(C)2019 Mouenis Anouar Tadlaoui et al. This is an open access article distributed under the Creative Commons Attribution (CC BY) License, which permits unrestricted use, distribution, and reproduction in any medium, provided the original work is properly cited.

\begin{abstract}
In the context of e-Learning systems, we can distinguish between two different types of settings. First, we have adaptable systems, which refer to the property of changing the system settings. The learner can change the behavior of the system. Then, the learner is able to customize the system in a specified way to fit the needs of users. The learner model is the key element to generate the adaptation of the system to each specific user. It's a representation of the learner information through which the system is based in to make it adaptable. We will present in this paper the implementation of a probabilistic learner model developed based on multi entities Bayesian networks and artificial intelligence, into a Course Creation Application Compatible with LMS-LD. The results presented in this work favor the implementation of a learner model to endorse the adaptation into some learning situations that the learners have followed during a year of testing.

\section{Keywords}

Learner model, Learner profile, Adaptive hypermedia, LMS-LD, Multi entity Bayesian networks, Artificial intelligence, Collaborative learning, E-learning personalization, Learning styles.
\end{abstract}

\section{Introduction}

The increasing power of computers makes it possible to process more and more complex applications, complexity coming from the many interacting entities that are autonomous, heterogeneous and evolving. The adjustment of this adaptive content, need a welldefined layout of the user.

The learner model is the key element to determine the way a system would behave with its users. In the case of absence of this model, the system would work in identically with all its users. We try in this paper, to implement the probabilistic learner model [1] in the instructional management systems-learning design (LMS-LD) course creation application (COPROLINE) [2], to give this application the possibility to adapt the learning path of each learner individually, following the three steps of implementation: data collection, initialization and the update of the learner model.

\footnotetext{
*Author for correspondence
} \section{6}

The main objective of this paper is presenting the results of the implementation of a probabilistic learner model developed based on artificial intelligence and multi entity Bayesian network into COPROLINE. And to present a study based on how this application will impact the path of each learner dynamically.

To achieve this objective, we will start by presenting the learner model in adaptive hypermedia (AHS), the characteristics and components of this model. Then, we will present the modalization of this model based on artificial intelligence and multi entity Bayesian networks. And, we will follow the steps of implementation by presenting the results of each step beginning by the data collection and the initialization and the update phase. The results presented in this work favoring the implementation of a learner model to endorse the adaptation into some learning situations that the learners have followed during a year of testing. 


\section{Materials and methods}

2.1Learner model: development and characteristics

We will begin by presenting the characteristics of the learner model in existing Adaptive Hypermedia Educational Systems (AHES), and the process of developing such a model to achieve an individual adaptation for each user.

2.1.1The characteristics of a learner model

A new generation of advanced learning systems must incorporate new pedagogical approaches that give the learner an active role in learning and building knowledge. These systems need to be more interactive, but most importantly, incorporate a more user-centric view. The purpose of these systems is to adapt the presentation of knowledge and help the learner to navigate through the graph composed of all pages and links [3-6].

The purpose of the learner's modeling is to give as complete and faithful a description as possible of all the aspects related to the behavior of this user. User models in AHS are generally compatible with IMS and public and private information (PAPI) standards. Just choose to use their structures and vocabularies to form attribute-value pairs for constructing models [7-8].

The major characteristics of the learner model could be reduced as we have published to [9-13]:

- Learning state

- Learner knowledge

- Characteristics of the learner

- Interactions between the system and the learner

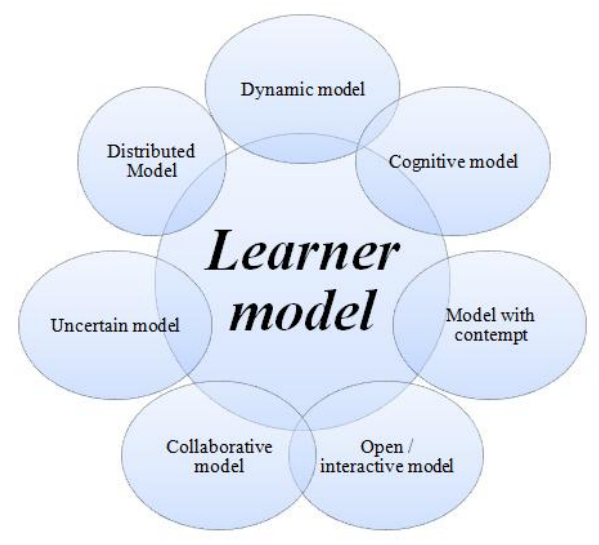

Figure 1 The characteristics of a learner model

Figure 1 represents the major characteristics of the learner model in adaptive systems. Any learner model developed relies on all of these characteristics to cover the huge amount of data collected required to an efficient and complete initialization of this model [14].

2.1.2Learner model's development process

The processes of developing a learner model in AHES consist of three major steps: the data collection phase, initializing the learner model and updating the model created.

In each of these phases, several methods and techniques are used. Choosing the right one is the key element to ensure adaptation in all the process of initialization. This process differs from system to system [15].

The update requires acquiring data about the learner behavior and adjusting the user model. Acquisition is the process of gathering learner inputs that correspond to learner interactions in AHES, such as the pages visited, the steps in solving a learner's problem, and so on [16-18].

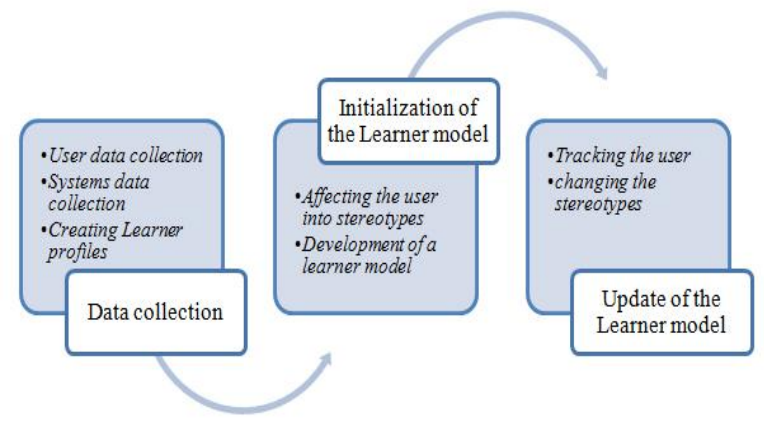

Figure 2 Learner model implementation process

Figure 2 shows the steps in developing a learner model. Beginning with the first phase, the data collected about the user and the system, this leads to creating a learner profile. The initialization phase and the update and tracking of this model.

2.1.3A probabilistic and dynamic learner model We have developed a probabilistic learner model based on artificial intelligence and multi entity Bayesian networks [19]. The main fragments of this learner model are:

- The fragment pre-test;

- The fragment learning situation;

- The fragment evaluation.

The pre-test fragment represents the initial tests that the learner has to take before being affected an initial stereotype or being given access to any learning situation. They are two types of these tests. One based on questions to test the learner knowledge. And the other based on the practice test his abilities. The learning activity fragment represents information 
about the learning activity. The learner must follow this activity during his or her learning path. The most important part that this fragment is composed of being the type of activity; they're in general two types: the interactive activity and the static activity.

The evaluation fragment represents the evaluation tests. The learner must take these tests at the end of each learning activity during their learning journey. This fragment has a condition in case of failure named remediation. This condition, works as an alert that aware the systems in case of failure and that include a call for the tutor to help the learning to take the next action.

For the learner fragment, there are three child nodes of this main node: The pre-test, the learning activity, and the evaluation. This fragment regroups all the other learner activity and information within a learning situation.

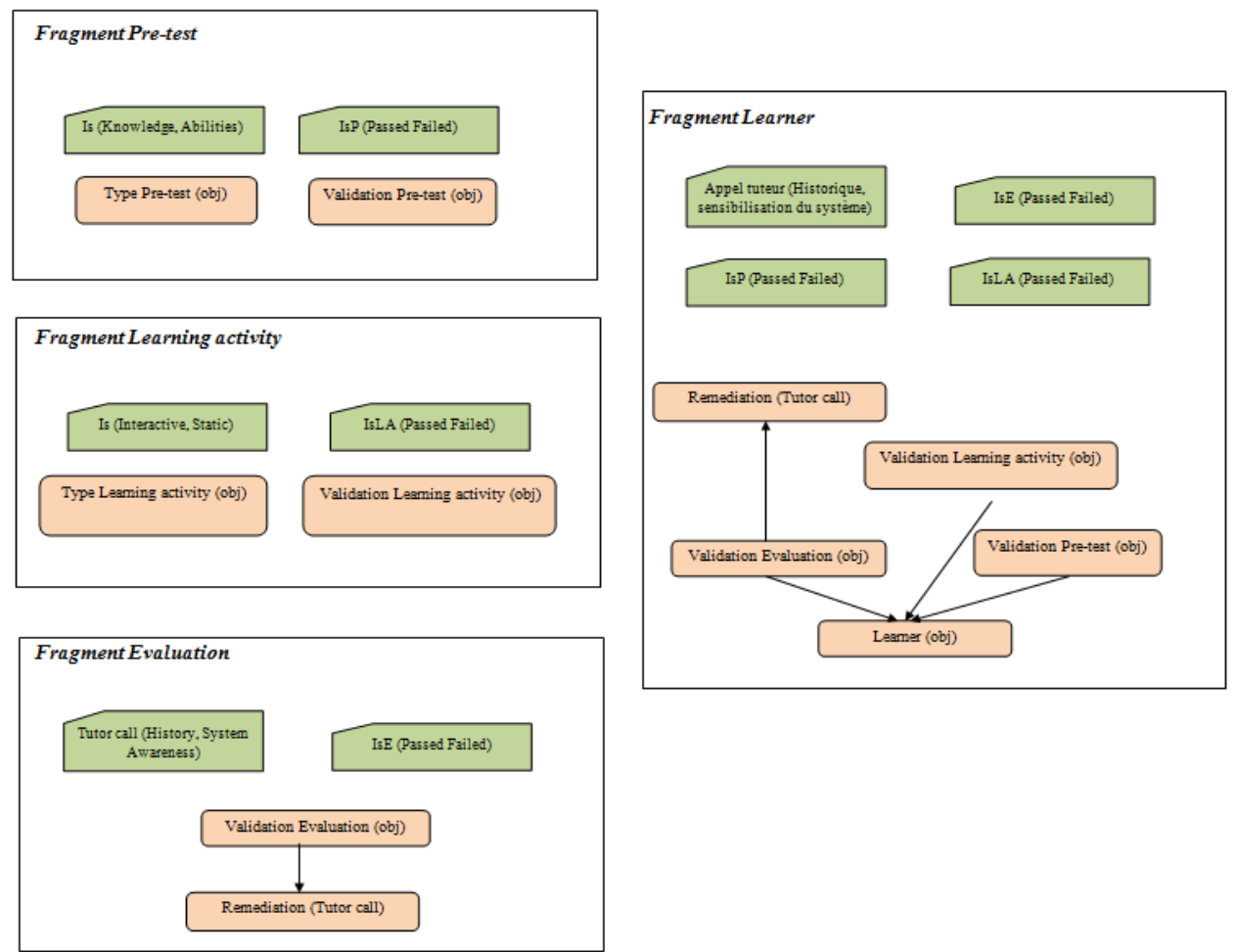

Figure 3 The M-theory of our probabilistic learner model

Figure 3 represents the multi-entity Bayesian network theory (M-theory) of the learner model we have developed [20]. This M-theory represents all the fragment of the learner model that composes the learning path that the learner has to take in order to success in a learning situation.

All this fragment has independent data input, which give us the possibility of tracking the learner situation in each stage of the learning situation. From the pretest that the learner takes before entering the learning situation, to the assessment that the learner takes at the end.

\subsection{The course creation application} (COPROLINE)

In this part, we will present the main architecture of the course creation application COPROLIN. The system composition and the learner section with all the functionalities.

2.2.1The main system architecture

COPROLINE is a system of production of educational projects compatible with the IMS-LD specification. COPROLINE composes of two sections: the teaching section and the learning section. 
The teaching section is already completed and operational, its main purpose is allowing teachers to connect through the Internet to their server to create and manipulate projects for learners either on the same computer environment or export them to other applications supporting the IMS- LD.

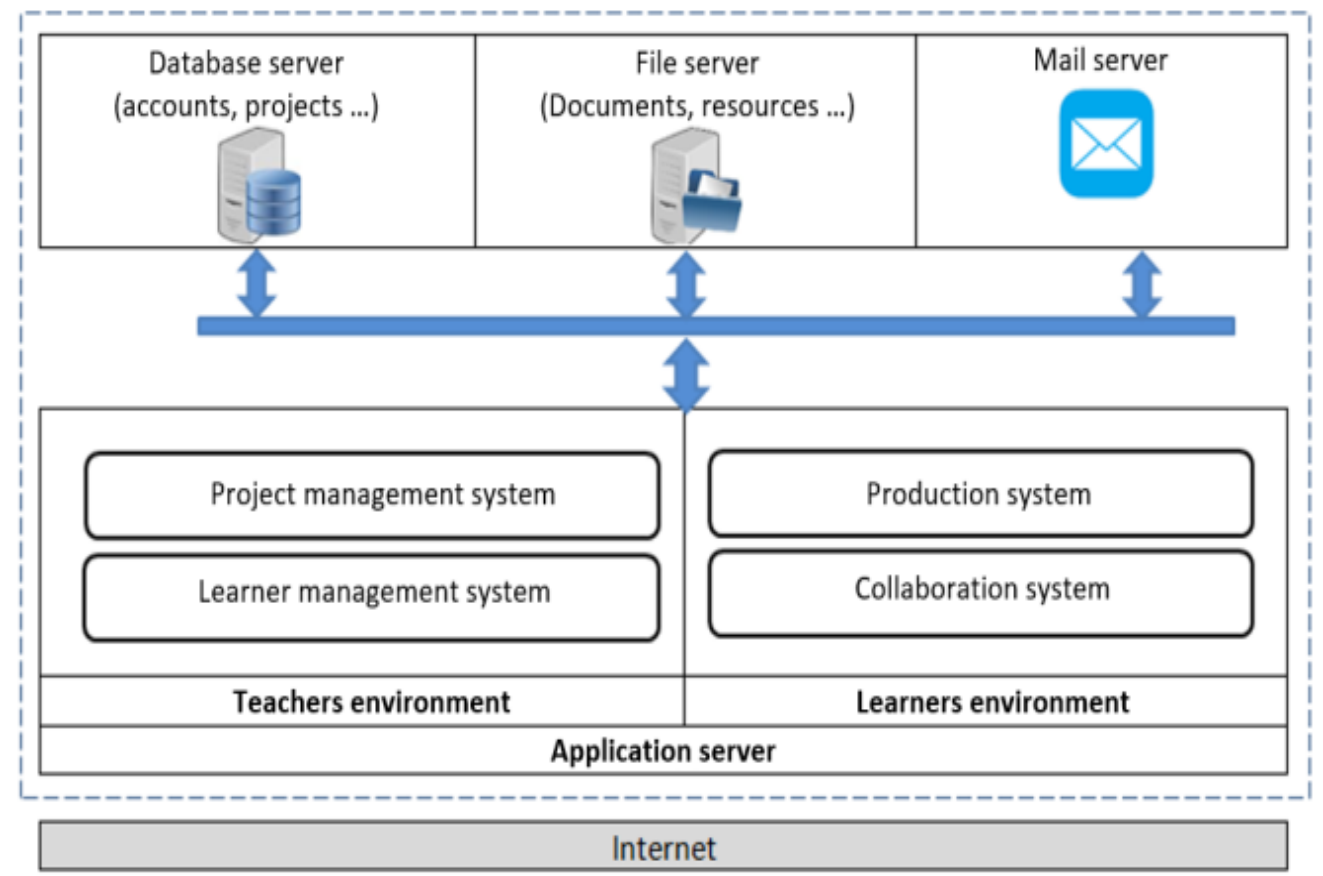

Figure 4 The general architecture of COPROLINE

The learning section concerns all the actions of the learners. In which we will present in this paper, it allows learners to connect through the Internet to its server to view their projects, perform the tasks requested, cooperate, collaborate and discuss to achieve their goals. [21]

Figure 4, represents the main architecture of COPROLINE. In which we can see the communication between the four main systems of the application in the application server and the servers to store data or communicate via e-mail.

In this architecture, we can distinguish two separate parts of the proposed model, representing each of the independent functionalities according to the type of connection:

The teaching environment: this is an environment for creating the educational project. It is designed to prepare and organize the design and development of projects in the form of tasks and sub-tasks to be executed by the learners and at the same time to manage the storage in project resources and files in the dedicated servers.
The learning environment: the two productions and collaboration systems make it possible, on the one hand, to offer a collaborative space in which many communication tools are accessible (Forum, Chat, email, etc.). On the other hand, this system is used to produce and share what is requested by the teacher. 2.2.3The general architecture of the learning section In this part we will detail the system allowing learners to perform tasks assigned by their teachers, communicate and collaborate in an environment specifically designed for these purposes, the collaboration system is based on three main services:

- Forum: This service allows learners to ask questions of other learners answer and check their colleagues' answers.

- Messaging: This is the service that allows learners to send and receive e-mails from their teachers or colleagues.

- Discussion: This is the instantaneous communication offered by the COPROLINE system in which learners can create discussion rooms for a group to which learners belong.

However, the production system consists of four services: 
- Production: this is the environment used by learners to produce and download the work in the form of computer files to the file server, it should be noted that the group coordinator is the element that can download the final product of the group.

- Resources: this service allows learners to consult the digital resources proposed by their teachers and which are necessarily linked to the projects.
- Projects: This is the environment in which learners can view their projects, tasks and subtasks.

- Training: it is a place reserved for the training of the learners in the realization of their tasks; this service can be used by the teacher to carry out certain trainings for his learners. [22]

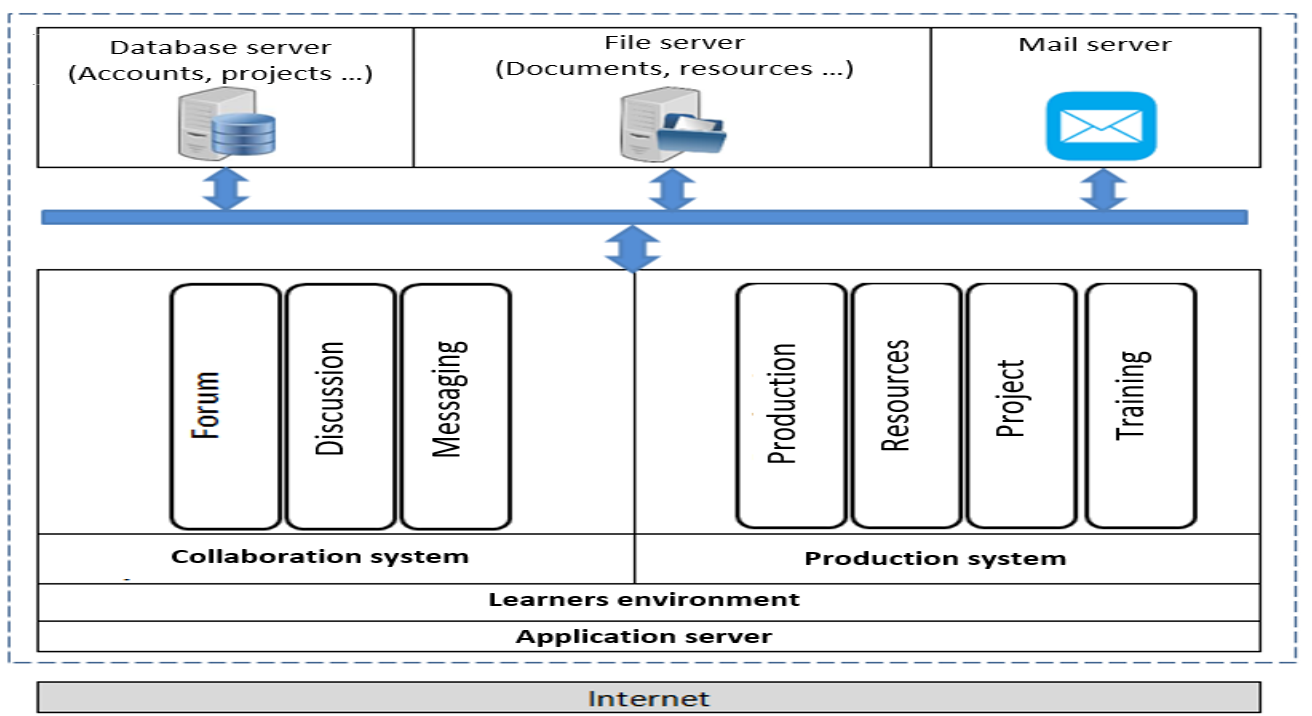

Figure 5 The system architecture of a learning situation in COPROLINE

Figure 5 presents the general architecture of the proposed learning section, and the interaction of the collaboration systems and the production systems within the application:

Collaboration system: Depending on the learners' needs for communication and collaboration, the collaboration system offers several features such as the participation or creation of forums, the triggering of a discussion, the sending of e-mails etc. In order to frame these functionalities, we will first model, using UML use case diagrams, the different tasks performed by the learners.

Production system: The learner who participates in the production of one of the projects proposed by the teachers is already registered on the platform by his teacher. Once enrolled, the learner uses mainly the production system to consult his project, his tasks and sub-tasks that are attributed to him. The following figure shows the use case diagram for a learner.

The learner can consult the documents and resources proposed by his teachers and which serve to facilitate tasks. He may also have the opportunity to participate in forums, to send a message to a teacher, to another learner. The learner can chat online with the teacher / trainer and can also edit his profile and view his results.

It should be noted that learners in the COPROLINE system who are part of the same working group, must have a coordinator who is defined from the beginning by his teacher, this type of learner is the only one who has the right to collect the productions of the group in the same result.

\subsection{The implementation of a probabilistic learning model in COPROLINE}

In this section, we will present the implementation of the probabilistic learner model implemented in COPROLINE.

2.3.1The initialization process of the learner model The purpose of the learner's modeling is to give as complete and faithful a description as possible of all the aspects related to the behavior of this user. User models in AHES are generally compatible with several standards. Just choose to use their structures and vocabularies to form attribute-value pairs for constructing models [23]. 


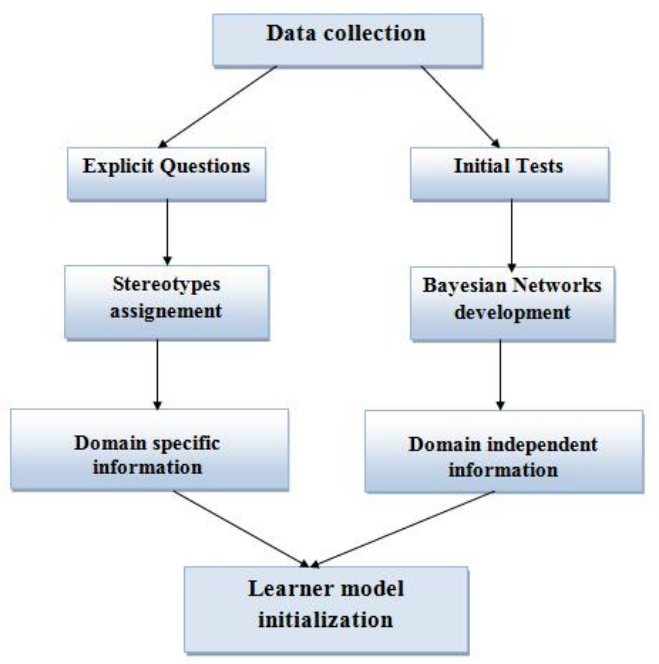

Figure 6 The process of initializing the learner model

The initialization of a learner model is about the transformation of the data gathered by the system into a well-defined model. A learner profile can also be initialized in three different ways: explicit questions, initial tests or stereotypes [24].

Figure 6 represents the process that we used to initialize our learner model. We proposed the use of explicit questions to gather the specific information about the learner, so the system could affect him with the adequate stereotype. And the use of the initial tests to gather the independent information about the user using Bayesian networks [25].

2.3.2The construction of a learner profile in COPROLINE

Figure 7 represents the process that we will use to create a learner profile in COPROLINE. The system will begin by asking multiple questions about the learner. Then store all these answers so we could use them to initialize a learner model.

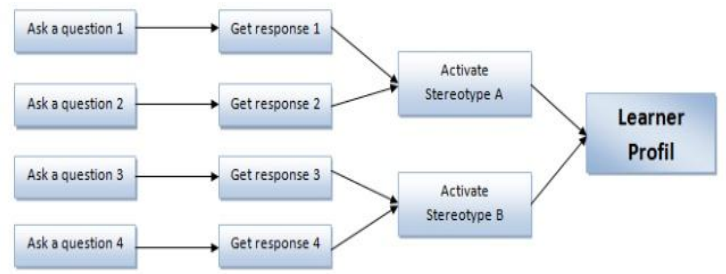

Figure 7 The construction of a learner profile

\subsubsection{The initial learner profile in COPROLINE}

Figure 8 presents a view of the initial learner profile based only on the basic information provided by the learner upon his registration in COPROLINE. The learner is requested to enter basic information about him, including his name, age, sex, place of birth, academic diplomat.

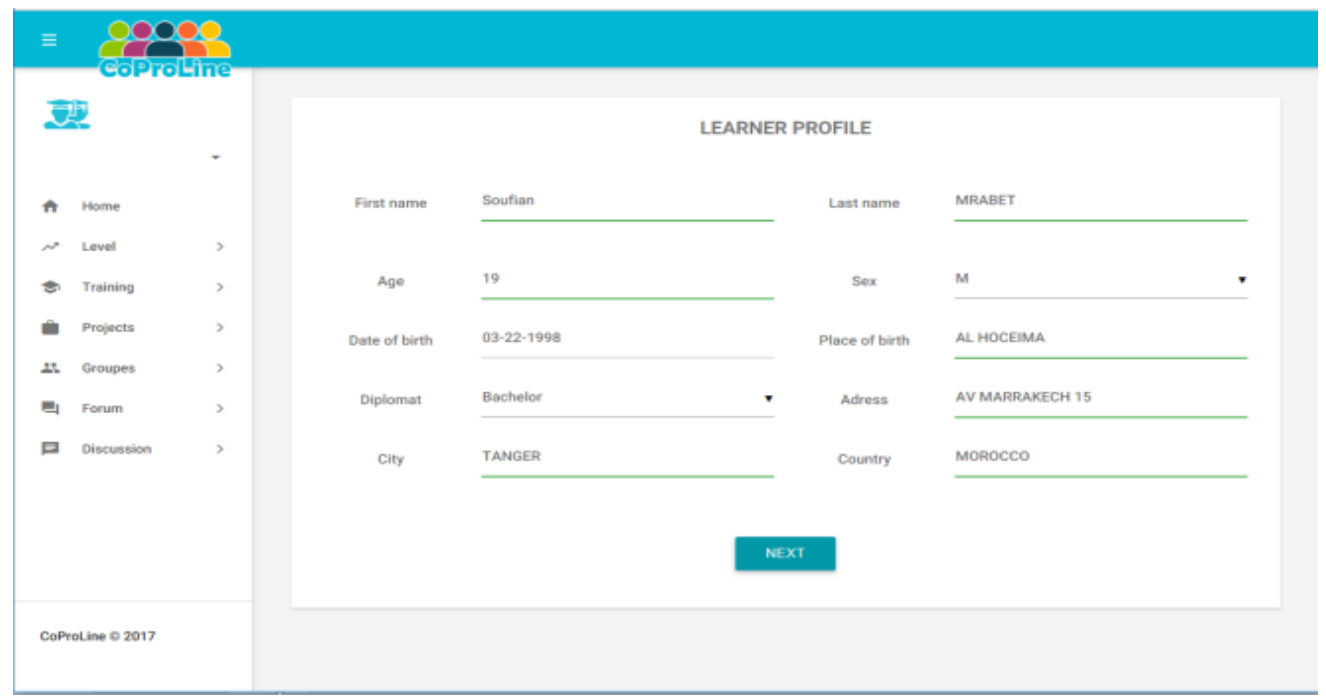

Figure 8 The initial learner profile in COPROLINE

All this information provided by the learner upon his registration, gives the systems an initial learner profile. This learner profile will keep growing upon taking the pretest to affect the adequate stereotype to the learner before assigning him to the proper learning situation.

2.3.2.2Pre-test explicit questions

Figure 9 presents a view of the explicit questions presented to the learner to take before assigning him the adequate 
stereotype. Every learner is asked to respond to different type of explicit question about a specific subject to test his/her level of knowledge of the subject to assign him to the adequate stereotype.

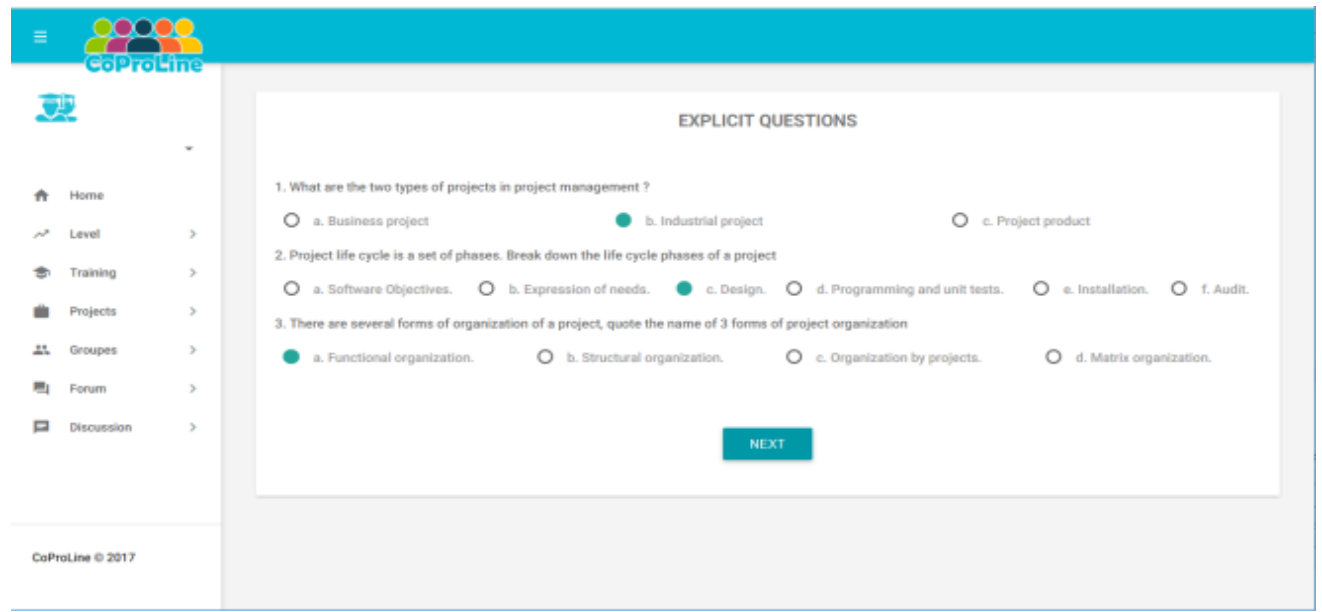

Figure 9 Explicit questions for the module project management

After finishing these explicit questions, a predefined stereotype is assigned to the learner. They are four levels of mastering a subject (novice, beginner, advanced and expert). The learners will be divided into the adequate level of mastering. Each tile the scores will get higher, the level of the learner will change. After the collection of the learner information, the system will affect each learner with the adequate stereotype.

\subsubsection{Affectation of stereotypes in COPROLINE}

The stereotype is a set of important impacts of the user. New learners will be classified according to their initial characteristics, each classifier is stereotyped. From the little time on information stereotyping, he is able to deduce many more new assumptions about the user. If the user information is detailed, easily and concretely, it will be converted to become more accurate. The term "hypothesis" refers to the belief of the system concerning the user, but this belief is not completely reliable, it is not temporary.

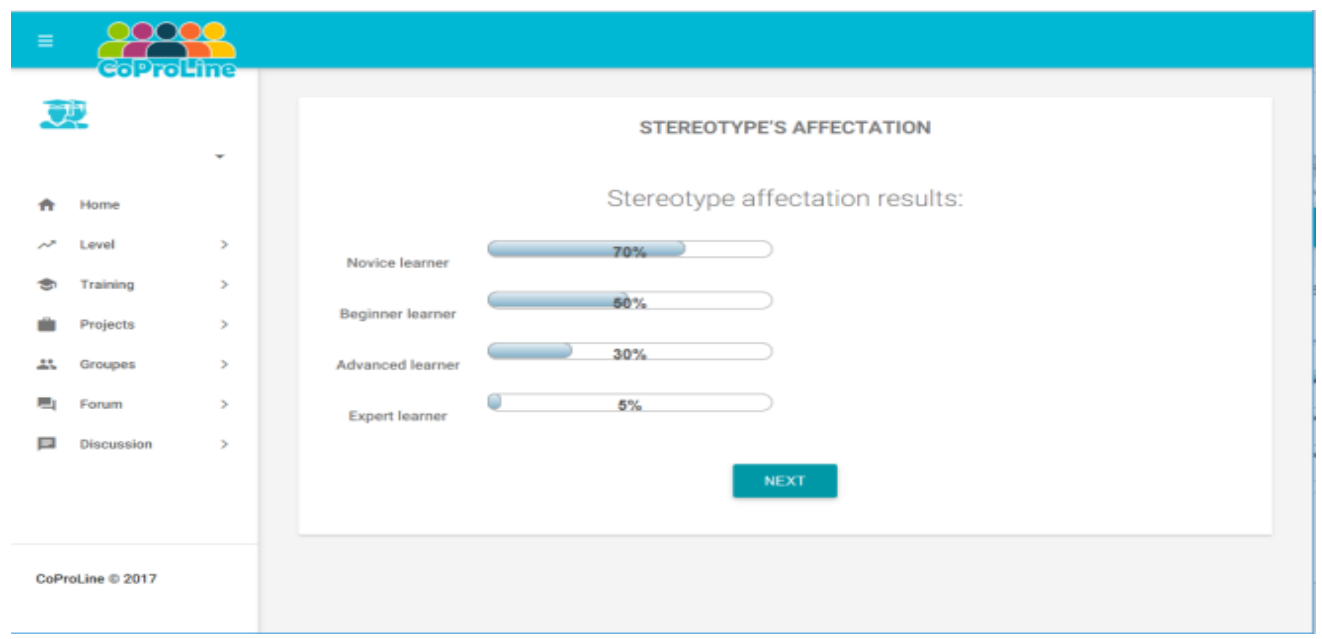

Figure 10 Stereotypes' affectation based on explicit questions

Figure 10 presents the result of the stereotype affectation for a learner in the project management module. We notice that the learner is assigned with the "Novice Learner" stereotype by $70 \%$ of accuracy, $60 \%$ accuracy for the stereotype "Beginner learner",
$30 \%$ of accuracy for "Advanced learner" and 5\% of accuracy for the stereotype "Expert learner".

There are three important components in a stereotype in COPROLINE, in which the system assigns and 
change the stereotype of each learner: trigger, inference and retraction [26, 27]:

-Trigger: is used to active a stereotype. In other word, it is a condition to affect a stereotype to learner, based on the test that the learner took in the learning situation. When 'Don't know project management" is activated, the stereotype "Novice learner" will be assigned to learner.

-Inference is inferring engine, responsible for deducing related information about user from stereotype. For example: if the learner is glued to "Expert Learner" stereotype, inference engine should take out both necessary and extra information such as: learner master Project management, Unified modeling language (UML), Operational research, Charge estimation.

-Retraction conditions are used to deactivate learner's stereotype. There is a circumstance: learner was assigned stereotype "Novice learner" at the beginning of course, but after learning process, learner knew thoroughly the project management module, so his stereotype "Novice learner" is no longer suitable. Event like "Learner do final Project management test very well" is condition to retract his stereotype "Novice learner" and he will be assigned a new appropriate stereotype - "Expert learner".

2.3.4Learner orientation in COPROLINE

After finishing the learner situation, the learner could access the results of their achievement for each element of the learning situation. Starting by presenting their grades in each learning situation and noticing the percentage of achievement for each element, as presented in Figure 11.

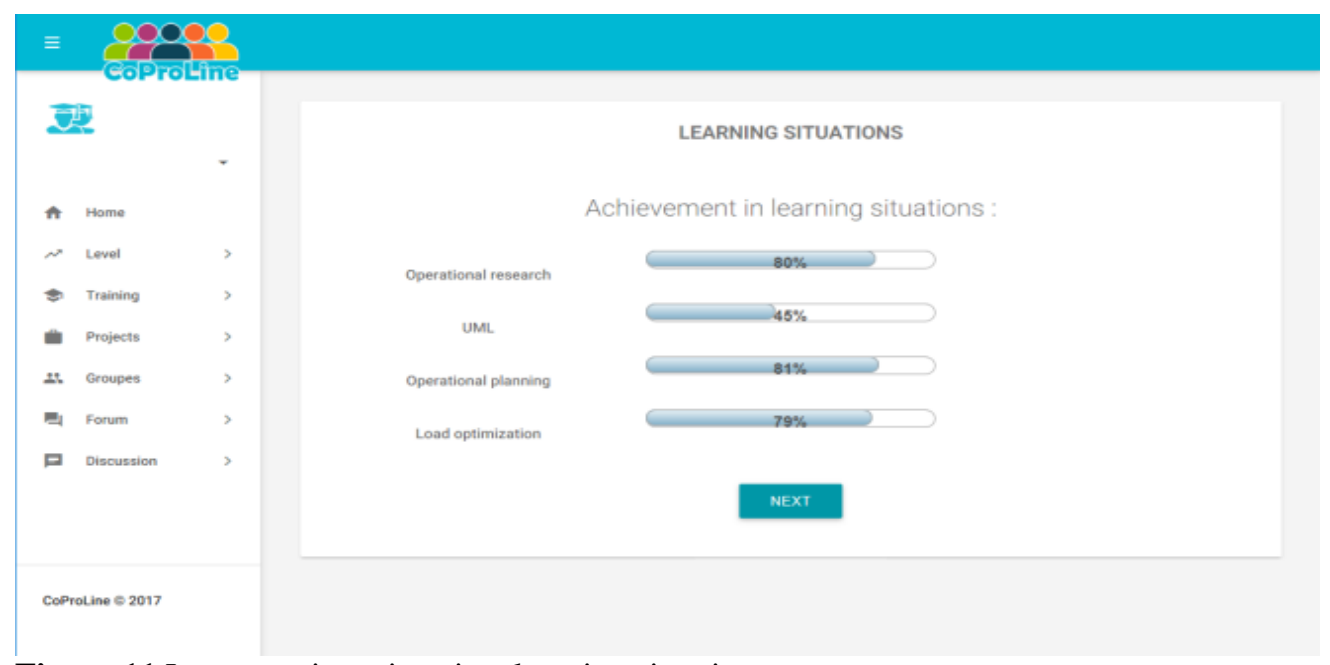

Figure 11 Learner orientations in a learning situation

In the example presented in Figure 11, the learner has accomplished an $80 \%$ of validation in the element of "Operational research", at $45 \%$ in the "UML" element, an $81 \%$ in the element of "Operational planning" and a $75 \%$ in the "Load optimization" element in the project management module.

Dependent on the results of each learner, the learning path will be determined for him/her. A condition of validation for each module is set at $75 \%$. If the learner accomplished this condition in all the elements of the learning situation, he will be granted the possibility of moving forward into the next learning situation. And if the condition is only valid for one or more element of the learning situation, then the system awareness will appear to guide the learner into the validation of the missing elements. 


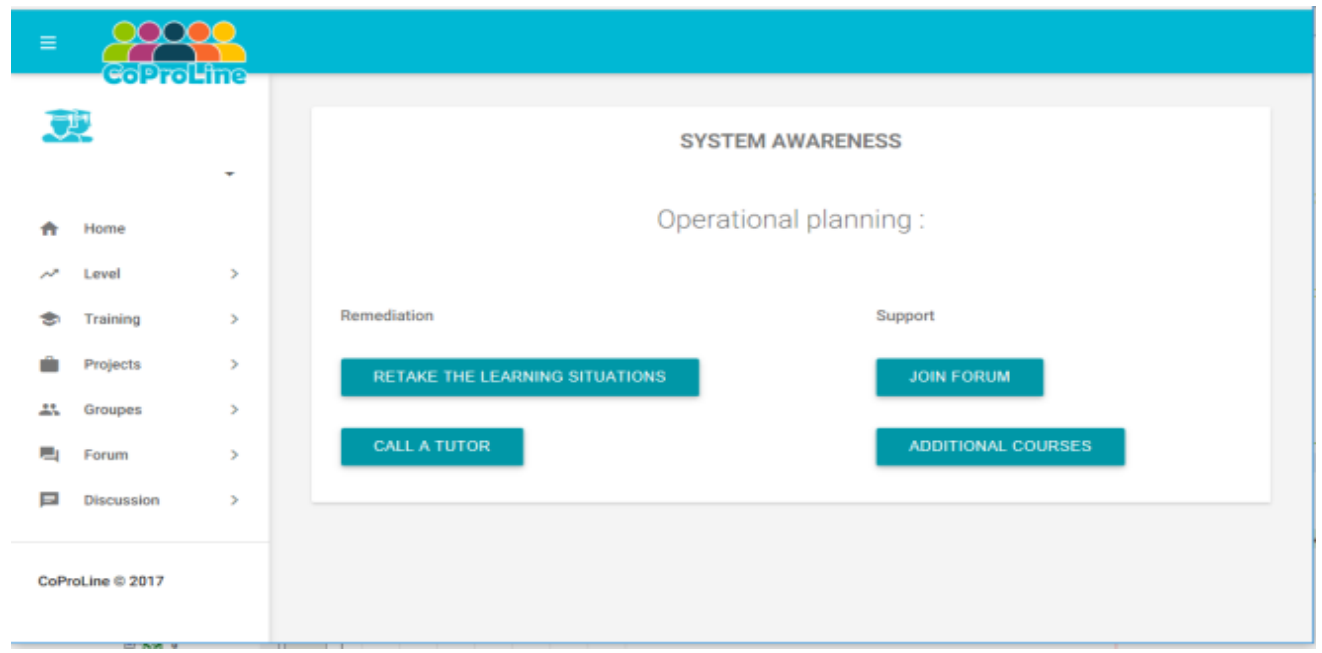

Figure 12 System awareness in a learning situation

Figure 12 present the system awareness page for the element "Operational planning", in which the learner didn't pass the validation percentage of $75 \%$. The system gives an option to the learner to choose between remediation and support to help him/her validate this element and then the whole learning situation.

In the remediation section, the learner has the possibility of retaking the learning situation element instantly or after a while to give him/her another chance to improve his/her knowledge and abilities of this element. Also, an option to contact a tutor is available for the learner in case of difficulties in this learning situation.

And in the support section, the learner has the possibility of joining a forum of discussion to work in pairs to improve his knowledge and abilities of this element. Also, an option of consultation of other course materials is available before retaking the learning situation all over again.

\section{Discussion}

The finding of this implementation clearly shows that using this course creation application will make it easier to track the evolution of each learner during all his/her learning path. This tracking could be possible only by using a probabilistic work frame as we have stated before. COPROLINE is, for now, the only system of production of educational projects compatible with the IMS-LD specification based on a probabilistic learner model. We have tried during the development of this application, to make it as selfdependent as possible. Starting by collecting data on the learner, after in the implementation of the learner 394 model, and finally in the update of this model during the learning path.

COPROLINE is part of our project of managing the learner model, that we have been working on for many years. This prototype that we presented in this paper has been used with an initial 100 learners from the Ecole Normale Superieure de Tétouan, from different specialties and levels. The results that we have presented to validate our hypothesis of the probabilistic management of the learner model using Artificial Intelligence.

\section{Conclusion and future work}

All adaptive e-learning systems are based on a learner model. We could not achieve an automatic adaptation of a system without a model that contains all the information about this user. The individual action and need will always vary from a user to another. That's why a dynamic or in this case a probabilistic view is critical. We presented in this paper, the implement of a probabilistic learner model in the LMS-LD Course creation application COPROLINE following the three steps of implementation: data collection, initialization and the update of the learner model. In order to give this application, the possibility of freely adapting the learning path of each learner.

The experiments presented in this paper are the results of testing our LMS-LD Course creation application COPROLINE for more than two years with different kind of learner after the implementation of a probabilistic model of the learner, using all the nodes as sensors to measure and evaluate the learner's module. And follow the 
progress of the learner during the learning situation. We suggest keeping working on adding more autonomy to this application. This version of COPROLINE is a work in progress that we are working on improving, especially with regard to the appearance of large data stored in the system. We suggest working more on the recommendation system of the application using machine learning extraction methods for better use of learner data.

\section{Acknowledgment}

None.

\section{Conflicts of interest}

The authors have no conflicts of interest to declare.

\section{References}

[1] Tadlaoui MA, Khaldi M, Carvalho RN. Bayesian networks for managing learner models in adaptive hypermedia systems: emerging research and opportunities. IGI Global. 2018.

[2] El Moudden F, Khaldi M, Souhaib A. Designing an IMS-LD model for collaborative learning. International Journal of Advanced Computer Science and Applications. 2015; 6(12):42-8.

[3] Mouenis AT, Mohamed K, Souhaib A. Towards probabilistic ontology based on Bayesian Networks. International Journal of Software and Web Sciences. 2014; 10(1):102-6.

[4] Hrich N, Lazaar M, Khaldi M. Improving cognitive decision-making into adaptive educational systems through a diagnosis tool based on the competency approach. International Journal of Emerging Technologies in Learning. 2019; 14(7):226-35.

[5] Gulbahar Y, Yildirim D. Towards an adaptive learning analytics framework. In society for information technology \& teacher education international conference 2019 (pp. 1025-32). Association for the Advancement of Computing in Education.

[6] Normadhi NB, Shuib L, Nasir HN, Bimba A, Idris N, Balakrishnan V. Identification of personal traits in adaptive learning environment: systematic literature review. Computers \& Education. 2019; 130:168-90.

[7] Mouenis AT, Souhaib A, Mohamed K. Learner modeling based on Bayesian networks. E-LearningInstructional Design, Organizational Strategy and Management. 2015:165-87.

[8] Tadlaoui MA, Aammou S, Khaldi M, Carvalho RN. Learner modeling in adaptive educational systems: a comparative study. International Journal of Modern Education and Computer Science. 2016; 8(3):1-10.

[9] Kay J. User modeling for adaptation. User Interfaces for all: Concepts, Methods, and Tools. 2001; 4:27194.

[10] De Koch NP. Software engineering for adaptive hypermedia systems. PhD Thesis, Verlag Uni-Druck, Munich. 2001.

[11] Pierrakos D, Paliouras G, Papatheodorou C, Spyropoulos CD, Karat J, Karat CM, et al. User modeling and user-adapted interaction. User Modeling and User-Adapted Interaction. 2001; 13 (4): 1-2.

[12] Castillo G, Gama J, Breda AM. Adaptive Bayes for a student modeling prediction task based on learning styles. In international conference on user modeling 2003 (pp. 328-32). Springer, Berlin, Heidelberg.

[13] Han B. Student modelling and adaptivity in web-based learning systems. Massey University New Zealand. 2001.

[14] Henze N, Nejdl W. A logical characterization of adaptive educational hypermedia. New Review of Hypermedia and Multimedia. 2004; 10(1):77-113.

[15] Tadlaoui MA, Khaldi M, Aammou S. Towards a learning model based on Bayesian networks. In EDULEARN14 Proceedings 2014 (pp. 3185-93). IATED.

[16] Tadlaoui MA, Souhaib A, Mohamed K. Development of Bayesian networks from unified modeling language for learner modelling. International Journal of Advanced Computer Science and Applications. 2015; 6(2): 139-44.

[17] Laskey KB, D'ambrosio B, Levitt TS, Mahoney S. Limited rationality in action: decision support for military situation assessment. Minds and Machines. 2000; 10(1):53-77.

[18] Da Costa PC, Laskey KB, Chang KC. PROGNOS: applying probabilistic ontologies to distributed predictive situation assessment in naval operations. International command and control research and technology symposium. 2009.

[19] Tadlaoui MA, Carvalho RN, Khaldi M. A learner model based on multi-entity Bayesian networks and artificial intelligence in adaptive hypermedia educational systems. International Journal of Advanced Computer Research. 2018; 8(37):148-60.

[20] El-Moudden F, Aammou S, Khaldi M. A tool to generate a collaborative content compatible with IMSLD. International Journal of Software and Web Sciences. 2014; 11(1):1-8.

[21] El Moudden F, Khaldi M. Towards integration of CopperCore services in application to generate collaborative online content compatible with IMS-LD. International Journal of Current Trends in Engineering \& Research. 2016; 2(6):198-204.

[22] Self JA. Formal approaches to student modelling. In student modelling: the key to individualized knowledge-based instruction 1994 (pp. 295-352). Springer, Berlin, Heidelberg.

[23] Tadlaoui MA, Carvalho RN, Khaldi M. The initialization of the learner model combining the Bayesian networks and the stereotypes methods. International Journal of Advanced Computer Research. 2017; 7(33):200-12.

[24] Webb GI, Pazzani MJ, Billsus D. Machine learning for user modeling. User Modeling and User-Adapted Interaction. 2001; 11(1-2):19-29.

[25] Park OC, Lee J. Adaptive instructional systems. Educational Technology Research and Development. 2003; 25:651-84. 
[26] Simko M, Bielikova M. Lightweight domain modeling for adaptive web-based educational system. Journal of Intelligent Information Systems. 2019; 52(1):165-90.

[27] Leonardou A, Rigou M, Garofalakis JD. Open learner models in smart learning environments. In cases on smart learning environments 2019 (pp. 346-68). IGI Global.

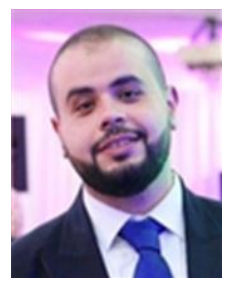

Mouenis Anouar Tadlaoui is a Research Scholar in Computer Sciences, at the Laboratory of Informatics, Research Operational and Statistic Applied (LIROSA) at Faculty of Sciences, Abdelmalek Essaadi University. His dissertation research, focus on managing the learner model in Adaptive Hypermedia Systems based on Bayesian methods and Artificial Intelligence. Mouenis have a Master's degree in Instructional design Multimedia Engineering, and a BSc in Web development from Abdelmalek Essaadi University in 2013 \& 2011. He has produced several technical outputs, including Books, Papers, Book Chapters, Technical Presentations, among others in the field of Computer Sciences. In research, his current interests include: Learner Modeling, Adaptive Web, Artificial Intelligence, Bayesian Networks and Machine learning.

Email: tadlaouimouenis@gmail.com

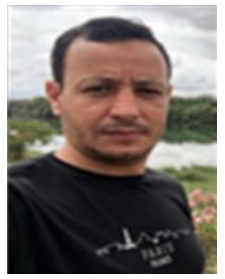

El Moudden Fauzi Is a PhD candidate in Computer Sciences, at the Laboratory of Informatics, Research Operational and Statistic Applied (LIROSA) at Faculty of Sciences, Abdelmalek Essaadi University. He has a Master degree in Instructional Design Multimedia Engineering at the École normale supérieure of Martil, Morocco in 2013. His current research focuses on: E-learning, Collaborative Learning and Pedagogy.

Email: fauzimoudden@gmail.com

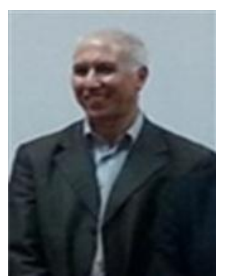

Mohamed Khaldi is a Pofessor at the The École normale supérieure at Abdelmalek Essaadi University, and he is with the Laboratory of Informatics, Research Operational and Statistic Applied (LIROSA) at Faculty of Sciences, Abdelmalek Essaadi University. Tétouan, Morocco.

Email: medkhaldi@yahoo.fr 